\title{
Effects of Estrogen on Fetal Rabbit Lung Maturation: Morphological and Biochemical Studies
}

\author{
SAVITA S. KHOSLA, G. J. WALKER SMITH, PATRICIA A. PARKS, AND SEAMUS A. ROONEY ${ }^{(40)}$ \\ Division of Perinatal Medicine, Departments of Obstetrics and Gynecology, Pathology, and Pediatrics, Yale University \\ School of Medicine, New Haven, Connecticut, and the John B. Pierce Foundation Laboratory, \\ New Haven, Connecticut, USA
}

\begin{abstract}
Summary
$17 \beta$-Estradiol $(0.44$ to $4.4 \mu \mathrm{g} / \mathrm{kg})$ was intramuscularly administered to pregnant rabbits on day 25 or 26 of gestation, and the fetuses were delivered by cesarean section $24 \mathrm{hr}$ later. On light microscopy, the lungs from the treated group had larger alveoli and thinner interalveolar septa than did those from the controls at the same gestational age. The lumen:septa ratio was $0.62 \pm 0.06$ in the control group and $0.88 \pm 0.05$ in the treated group $(P<$ 0.01 ). Blood vessels in the lungs of the treated group were also more mature than were those in the control group. Alveolar epithelial cells consisted of $52 \%$ undifferentiated, $21 \%$ type II, and $27 \%$ type I cells in the control group. In the estrogen-treated group, the corresponding distribution was 25,29 , and $45 \%$. There were $0.82 \pm 0.16$ lamellar bodies per alveolar cell in the treated group compared to $0.38 \pm 0.06$ in the controls $(P<0.05)$. Estrogen decreased fetal lung glycogen content from $247 \pm 15 \mu \mathrm{g} / \mathrm{mg}$ protein to $70 \pm 9$ on day 26 and from $103 \pm 13$ to $13 \pm 2$ on day $27(P<0.001)$. Estrogen administration increased the rate of incorporation of choline into phosphatidylcholine in fetal lung slices, decreased the rate of thymidine incorporation into DNA, but had no effect on the rates of incorporation of ethanolamine into phosphatidylethanolamine or of leucine into protein. These data indicate that estrogen accelerates the rate of fetal lung maturation. It appears to stimulate lung differentiation at the expense of lung growth.
\end{abstract}

\section{Speculation}

Estrogen may be involved in the physiologic control of fetal lung maturation and pulmonary surfactant production.

We have previously shown that administration of $17 \beta$-estradiol to pregnant rabbits at 25 to 26 days gestation (term is 31 days) accelerates fetal lung maturation and stimulates production of pulmonary surfactant $(16,17)$. Thus, maternal estrogen administration has the following effects on the fetal lung: it increases the amount of total phospholipid and phosphatidylcholine as well as the phosphatidylcholine:sphingomyelin ratio in lung lavage (17), it increases the rate of choline incorporation into phosphatidylcholine in lung slices (16), and it increases the activities of pulmonary cholinephosphate cytidylyltransferase and lysolecithin acyltransferase (16), enzymes involved in the synthesis of total and disaturated phosphatidylcholine, respectively (33). Gross et al. (12) reported that estrogen accelerates maturation of fetal rat lung in organ culture. This finding suggests that estrogen has a direct effect on the fetal lung.

The purpose of the present study was to further characterize the effects of estrogen on fetal lung maturation. Inasmuch as there are distinct morphological changes during maturation of the fetal lung (2), we examined the effects of estrogen on these parameters of lung maturation. In addition, we determined the effect of estrogen on lung glycogen content because this decreases toward the end of gestation in a number of species $(4,23,36)$, and it has been postulated that glycogen may provide substrate or energy for surfactant phospholipid synthesis in fetal lung $(18,23)$. Finally, we examined the effect of estrogen on the rate of synthesis of a nonsurfactant lung phospholipid, phosphatidylethanolamine, as well as on that of lung protein and DNA.

\section{MATERIALS AND METHODS}

\section{ANIMALS}

Pregnant rabbits (New England White) whose time of breeding was known to within $2 \mathrm{hr}$ were obtained from Plummer Rabbitry, Grafton, VT. The day of mating was considered day $0.17 \beta-$ Estradiol in propylene glycol was administered to the doe intramuscularly on days 25 or 26 of gestation. Control animals were similarly administered vehicle alone. Twenty-four hr later, the does were killed with intravenous sodium pentobarbital $(80 \mathrm{mg} /$ $\mathrm{kg}$ ), and the fetuses were delivered by cesarean section. The newborns were killed by decapitation.

\section{CHEMICALS}

Radioisotopes were obtained from New England Nuclear Corp., Boston, MA; mithramycin (Mithracin) was obtained from Pfizer Laboratories, New York, NY, and other biochemicals were obtained from Sigma Chemical Co., St. Louis, MO. Other chemicals were reagent grade or better.

\section{MORPHOLOGY}

Lungs were immediately excised and fixed in $10 \%$ formalin for light microscopy or in 3\% glutaraldehyde and processed as described previously (10) for electron microscopy. The lungs were inflated to intrathoracic volume with the fixative. Only the right apex was used for the morphologic studies. Morphologic changes in both light and electron microscopic preparations were quantitated. Changes in air spaces were quantitated by the point counting technique described by Weibel (37). Light microscopic slides (1 to 2 per fetus) were prepared from 2 to 3 fetuses from each of 12 control and 20 estrogen-treated litters. Each slide was projected onto a screen onto which was also projected a grid with 100 equidistant points. The ratio of the number of points falling on air spaces to those falling on the epithelium or interstitium was measured. Each slide was projected twice.

One or two blood vessels of 50 to $100 \mu \mathrm{m}$ diameter with an identifiable muscular media near a cartilaginous bronchus were examined from 1 to 2 fetuses from eight control and eight estrogen- 
treated litters. The ratio of the lumen diameter to the thickness of the blood vessel wall was measured on photomicrographs.

Electron micrographs of 50 to 150 epithelial cells per litter from five control and six estrogen-treated litters were examined. Only cells with a completely identifiable outline and nucleus were included. The epithelial cells were categorized into three groups: undifferentiated, type II, and type I cells. Tall columnar cells with elongated basal nuclei containing large amounts of glycogen and with relatively few microvilli on the apical surface were identified as undifferentiated cells. Cuboidal cells with large numbers of microvilli on the luminal surface containing lamellar bodies and appreciable amounts of glycogen were classified as type II cells. Cuboidal or flat cells with cytoplasmic extensions devoid of glycogen were classified as type I cells. Lamellar bodies in type II cells were counted. Lamellar bodies in the lumen were also noted. In two-dimensional photographs, the apparent increase in lamellar bodies could be due to increased size or increased numbers.

Morphometric data from each litter were pooled for statistical analysis.

\section{GLYCOGEN ANALYSIS}

Lungs and livers were rapidly excised, immediately frozen in acetone-solid $\mathrm{CO}_{2}$, and stored at $-70^{\circ} \mathrm{C}$ until analyzed. Glycogen was measured fluorometrically as described previously (23).

\section{INCORPORATION OF PRECURSORS INTO LIPIDS, PROTEIN, AND} DNA IN SLICES

Freshly excised lungs were chopped into $0.5 \mathrm{~mm}$ thick slices with a Mcllwain tissue chopper (Brinkmann Instruments, Inc., Westbury, NY). After a 10 min preincubation, the slices ( 2 to 6 $\mathrm{mg}$ protein) were incubated in Krebs-Ringer phosphate buffer

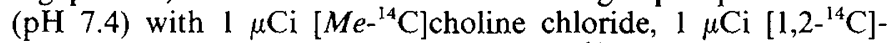
ethanolamine hydrochloride, $2 \mu \mathrm{Ci} \mathrm{L}-\left[U_{-}{ }^{14} \mathrm{C}\right]$ leucine, or $30 \mu \mathrm{Ci}$ $\left[\mathrm{Me}^{3} \mathrm{H}\right]$ thymidine for $1 \mathrm{hr}$ with shaking. Only tracer amounts of choline and ethanolamine were used, but the concentration of leucine and thymidine in the incubation mixture was $0.2 \mathrm{mM}$. Under these conditions, the rates of choline and ethanolamine incorporation into phosphatidylcholine and phosphatidylethanolamine, respectively, were linear for at least $3 \mathrm{hr}$, whereas those of leucine and thymidine into protein and DNA, respectively, were linear for at least $1.5 \mathrm{hr}$. The reactions were stopped in ice-water, and the slices were thoroughly washed with ice-cold $0.9 \% \mathrm{NaCl}$ solution. The tissue was homogenized, and aliquots were removed for protein assay and for product measurement. Lipids were extracted, and radioactive phosphatidylcholine and phosphatidylethanolamine were measured as described previously (34). Aliquots for measurement of radiolabeled protein and DNA were applied to $2.3 \mathrm{~cm}$ disks of Whatman $3 \mathrm{MM}$ filter paper which were immediately plunged into ice-cold $10 \%$ trichloroacetic acid containing $0.2 \mathrm{mM}$ leucine or thymidine, respectively (24). After $1 \mathrm{hr}$, the $10 \%$ trichloroacetic acid was decanted, and the disks were resuspended in ice-cold 5\% trichloroacetic acid twice for $15 \mathrm{~min}$ each and in ethanol:diethyl ether $(50: 50 \mathrm{v} / \mathrm{v})$ for $45 \mathrm{~min}$. The disks were finally rinsed with diethyl ether and air dried, and the radioactivity content was measured in Econofluor (New England Nuclear Corp.).

Variations in slice thickness as well as in uptake of the radiolabeled precursor into the slice could influence the apparent rate of incorporation of precursor into product. In measuring the rate of incorporation of choline into phosphatidylcholine in fetal lung slices, Epstein and Farrell (7) corrected for this by measuring the precursor radioactivity in the upper (aqueous) phase of the chloroform:methanol:water extraction mixture. We have similarly corrected the rates of incorporation of choline and ethanolamine into phosphatidylcholine and phosphatidylethanolamine, respectively. We have made a similar adjustment in the case of protein and DNA synthesis. Aliquots of the homogenized slices were applied to filter paper disks and dried, and the radioactivity content was measured. The difference between the total radioactivity on the disk and the radioactivity after the washing procedure (macromolecular radioactivity) was taken as precursor radioactivity.

\section{DRY WEIGHT, PROTEIN, AND DNA MEASUREMENTS}

Dry weights were obtained on lyophilized lungs. Protein content was assayed by the procedure of Lowry et al. (21) using bovine serum albumin as standard. DNA was assayed by the mithramycin-binding assay described by Hill and Whatley (15).

\section{STATISTICS}

Statistical analyses were carried out with Student's $t$ test for independent variables.

\section{RESULTS}

On light microscopy, the lungs of the estrogen-treated animals at 26 days gestation appeared more mature than did those of the controls. Figure 1 shows that the air spaces were larger in the treated group than in the controls. The interstitial tissue in the treated group was generally 1 to 3 cells thick compared to 3 to 5 cells thick in the control group. Point-counting morphometric analysis showed that the ratio of alveolar space to interstitium increased by $42 \%$ from $0.62 \pm 0.06$ (S.E.) in the control group to $0.88 \pm 0.05$ in the estrogen-treated group $(\mathrm{P}<0.01)$.

The effect of estrogen on fetal lung blood vessels at 26 days gestation is shown in Figure 2 and Table 1. Blood vessels from the estrogen-treated group appeared more mature than did those in the control group. The lumen appeared larger and the wall thinner. These changes were quantitated by morophometric analysis (Table 1). Blood vessels of approximately the same size were examined in both groups. The lumen diameter was $62 \%$ greater in the estrogen-treated group than in the controls. There was a tendency towards thinner walls in the estrogen-treated group, but this change was not statistically significant. However, the lumen diameter-to-wall thickness ratio was twice as great in the treated group as in the controls.

The effects of estrogen on fetal rabbit lung at 27 days gestation at the electron microscopic level are summarized in Table 2 . There were $67 \%$ more type I epithelial cells and $52 \%$ fewer undifferentiated epithelial cells in the estrogen-treated group than in the control group. These changes were statistically significant. There were also $38 \%$ more type II cells in the treated group, but this change was not statistically significant. On the other hand, lamellar bodies appeared twice as frequently in alveolar lining cells in the treated group than the control group. Representative electron micrographs are shown in Figure 3. Loss of glycogen in the estrogen-treated group was one of the most striking observations. Another feature of the treated group was that most of the type I cells had very long, thin cytoplasmic extensions so that often the alveolar capillary barrier was reduced to a thin septal structure reminiscent of adult lung. Many of the alveoli were lined with only one or two such cells. This feature was almost entirely absent in the control group. Lamellar bodies were frequently seen in the alveolar lumen of the treated group (Fig. 3C) but very rarely in that of the control group.

The effect of estrogen on fetal lung glycogen content is shown in Table 3. The amount of glycogen in the lungs of control animals decreased significantly between 26 and 27 days gestation. There was only $42 \%$ as much glycogen at 27 days as at 26 days $(P<$ $0.001)$. Estrogen administration reduced the amount of lung glycogen by $72 \%$ at 26 days and by $87 \%$ at 27 days. The effect of estrogen on lung glycogen was dose dependent (Fig. 4). There was only a $34 \%$ decrease at $0.44 \mu \mathrm{g} / \mathrm{kg}$ but the maximum decrease was obtained at $1.1,2.2$ and $4.4 \mu \mathrm{g} / \mathrm{kg}$.

In contrast to the lung, estrogen had no effect on fetal liver glycogen content (Table 3 ). It is of interest that at the stage of gestation examined the glycogen content in the lung was consid- 

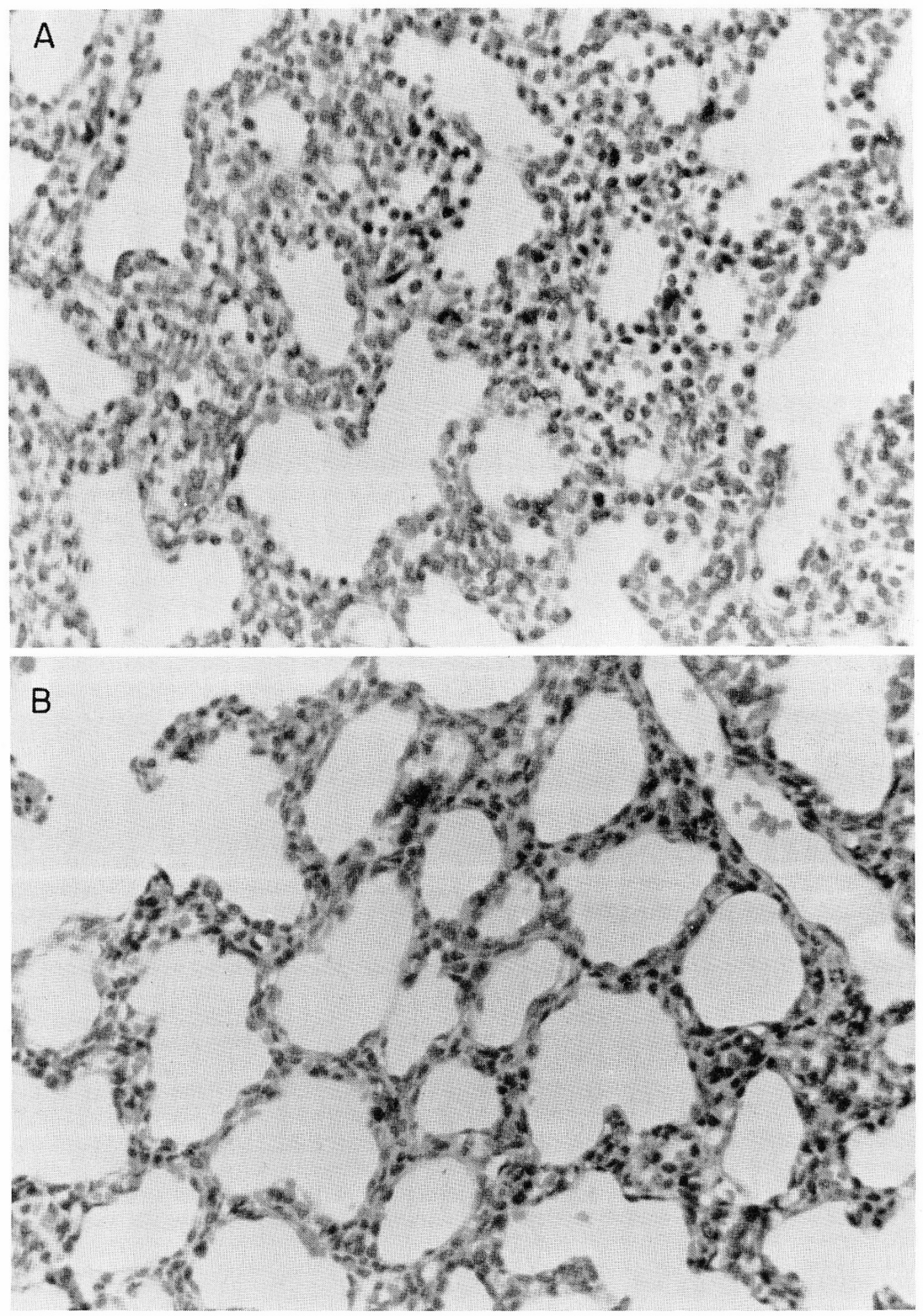

Fig. 1. Histologic appearance of control $(A)$ and estrogen-treated $(B)$ fetal rabbit lungs on day 26 of gestation after administration of $17 \beta$-estradiol $(4.4 \mu \mathrm{g} / \mathrm{kg}$ ) or vehicle to the doe on day 25 (hematoxylin and eosin; original magnification, $\times 250$ ).

erably greater than that in the liver. In contrast to the lung, liver glycogen increases towards the end of gestation (36).

We have previously shown that estrogen stimulates the rate of synthesis of phosphatidylcholine in fetal rabbit lung (16). To determine if this is a specific effect on phosphatidylcholine synthesis or if the rates of synthesis of other lung phospholipids are also stimulated, we examined the effect of estrogen on the rate of incorporation of ethanolamine into phosphatidylethanolamine in fetal lung slices. To determine if estrogen has a general effect on lung growth, we also measured its effect on the rates of incorporation of leucine into protein and of thymidine into DNA. In these experiments, to ensure that the stimulatory effect of estrogen 
on phosphatidylcholine synthesis occurred, we also measured the rate of choline incorporation into phosphatidylcholine. The data are shown in Table 4. Estrogen stimulated the rate of choline incorporation into phosphatidylcholine by $44 \%$ but had no effect on the rate of incorporation of ethanolamine into phosphatidylethanolamine or of leucine into protein. On the other hand, it decreased the rate of thymidine incorporation into DNA by $44 \%$.

In the slice studies, pool sizes of the various precursors and intermediates are unknown. Thus, a change in pool size could alter the rate of radioisotope incorporation. Nevertheless, changes in the rate of choline incorporation into phosphatidylcholine have been correlated with changes in enzyme activities in previous studies on the effects of hormones on fetal lung maturation $(5,16$, 34 ). Thus, rates of incorporation may approximate rates of synthesis.

To determine if the decrease in the rate of incorporation of

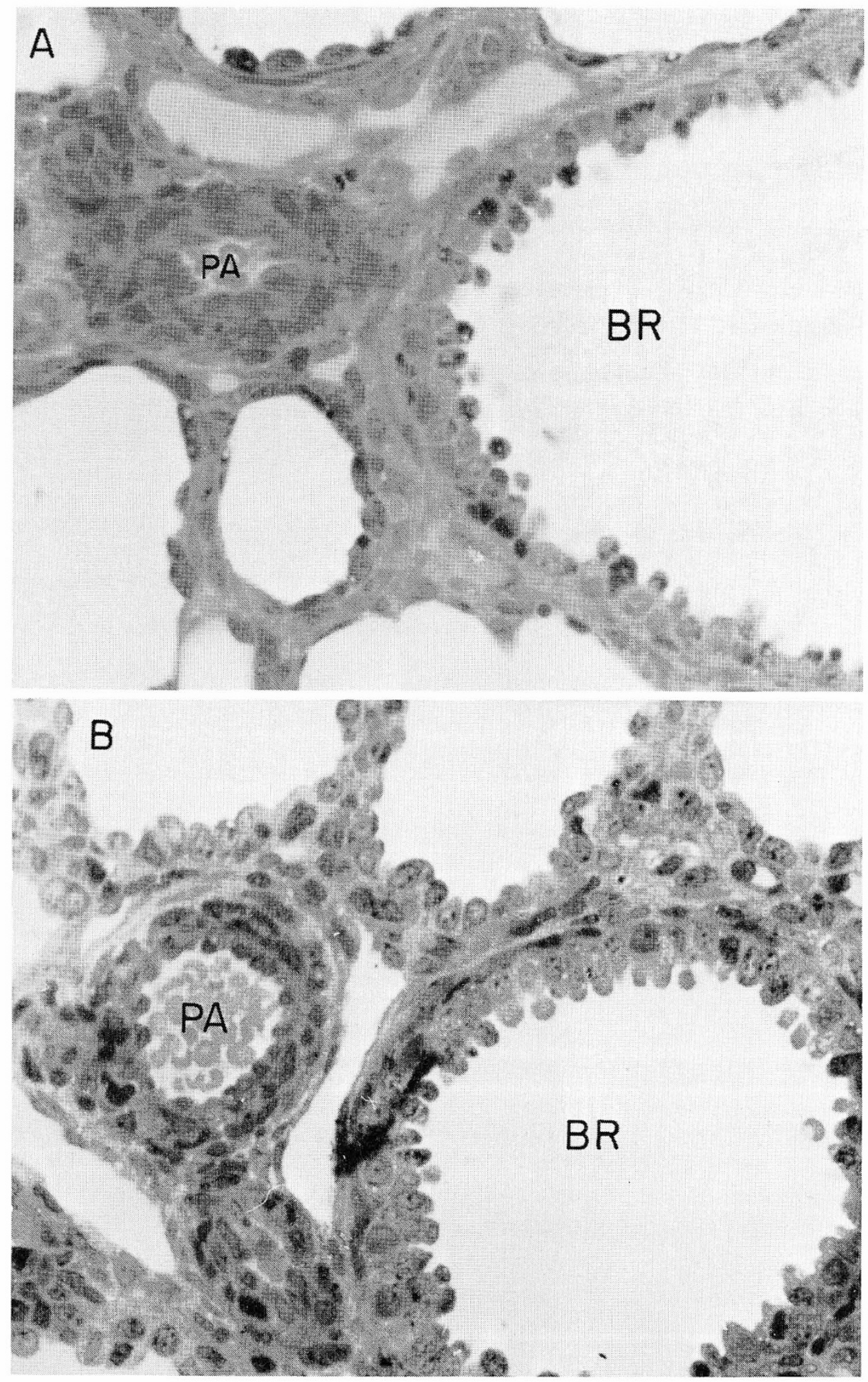

Fig. 2. Pulmonary arteries from lungs described in Figure 1. $A$, control; $B$, estrogen-treated; $P A$, pulmonary artery; $B R$, bronchus (hematoxylin and eosin; original magnification, $\times 250$ ). 
Table 1. Effect of $17 \beta$-estradiol on fetal rabbit lung blood vessels ${ }^{1}$

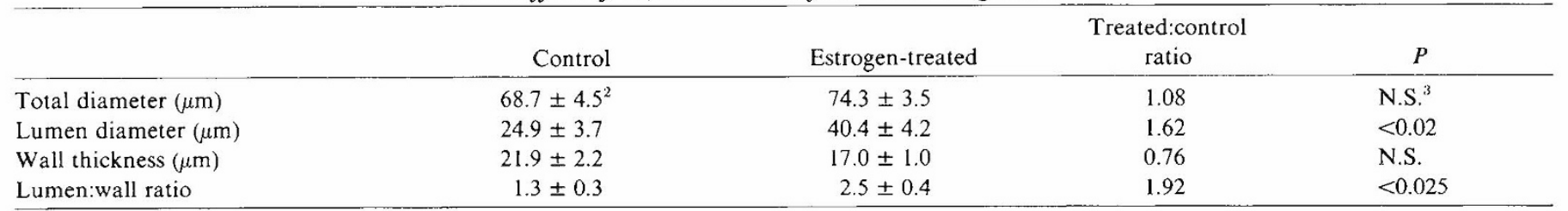

${ }^{1} 17 \beta$-Estradiol $(4.4 \mu \mathrm{g} / \mathrm{kg})$ or vehicle was administered to the doe on day 25 of gestation, and the animals were killed on day 26 . One or two blood vessels, 50 to $100 \mu \mathrm{m}$ in diameter, from one to two fetuses in each of eight control and eight estrogen-treated litters were examined. Mean values from each litter were analyzed statistically.

${ }^{2}$ Mean \pm S.E.

${ }^{3}$ N.S., not significant $(P>0.05)$.

Table 2. Effect of 17ß-estradiol on fetal rabbit lung epithelial cells ${ }^{1}$

\begin{tabular}{lcccc}
\hline \multicolumn{1}{c}{ Cell type } & $\begin{array}{c}\text { Control } \\
\text { (\% of total) }\end{array}$ & $\begin{array}{c}\text { Estrogen-treated } \\
\text { (\% of total) }\end{array}$ & $\begin{array}{c}\text { Treated:control } \\
\text { ratio }\end{array}$ & $P$ \\
\hline Undifferentiated & $52 \pm 9^{2}$ & $25 \pm 5$ & 0.48 & $<0.025$ \\
Type II & $21 \pm 4$ & $29 \pm 3$ & 1.38 & N.S. ${ }^{3}$ \\
Type I & $27 \pm 7$ & $45 \pm 4$ & 1.67 & $<0.05$ \\
Lamellar bodies per epithe- & $0.38 \pm 0.06$ & $0.82 \pm 0.16$ & 2.16 & $<0.05$
\end{tabular}

lial cell

${ }^{1} 17 \beta$-Estradiol $(4.4 \mu \mathrm{g} / \mathrm{kg})$ or vehicle was administered to the doe on day 26 of gestation, and the fetuses were delivered on day 27. In this experiment, 50 to 150 epithelial cells from each of five control and six estrogen-treated litters were examined. The means from each litter were analyzed statistically.

${ }^{2}$ Mean \pm S.E.

${ }^{3}$ N.S., not significant $(P>0.05)$.
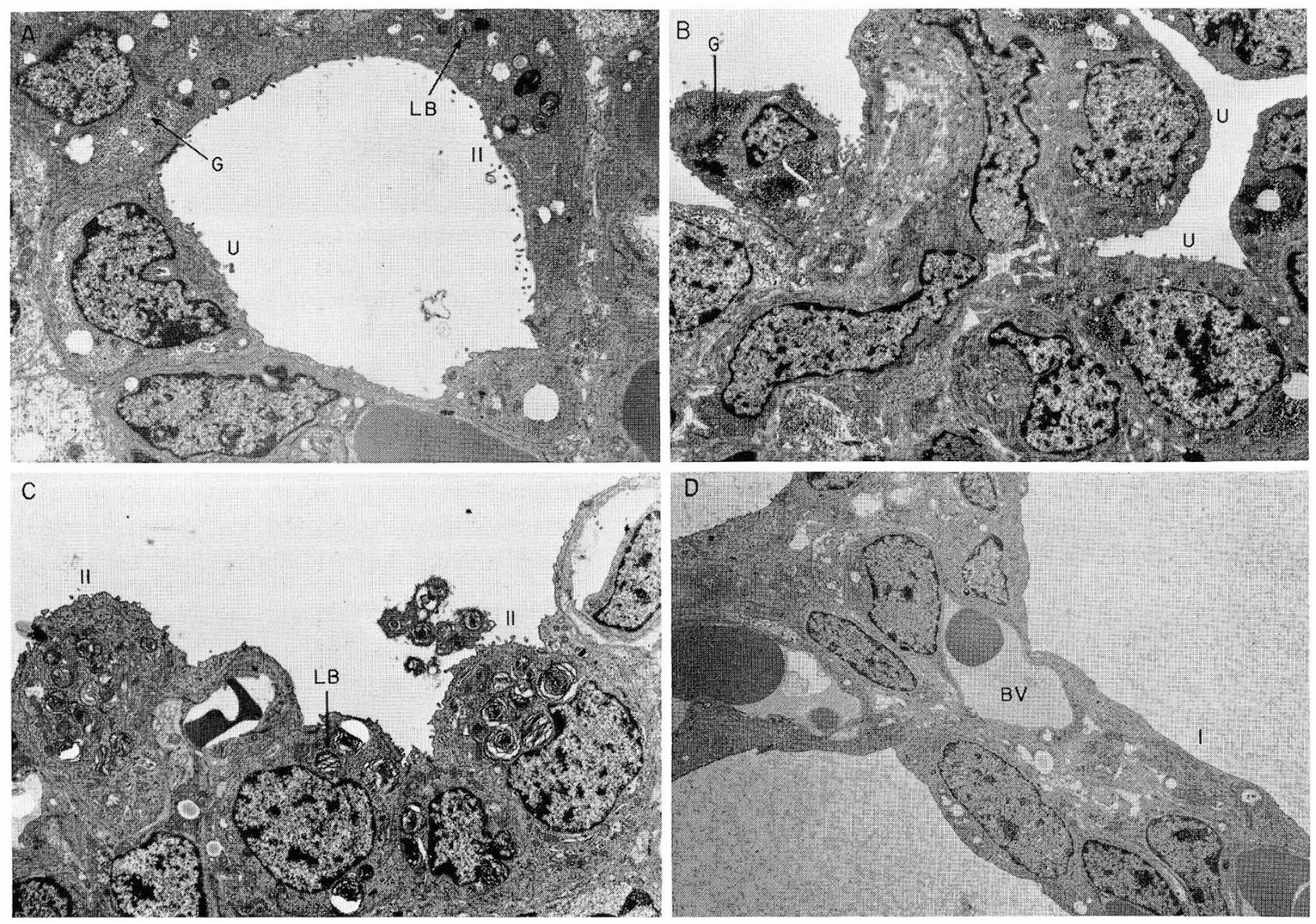

Fig. 3. Electron micrographs of control $(A$ and $B)$ and estrogen-treated $(C$ and $D)$ fetal rabbit lungs on day 27 of gestation after maternal administration of $17 \beta$-estradiol $(4.4 \mu \mathrm{g} / \mathrm{kg})$ or vehicle on day $26(A, \times 6300 ; B, \times 6000 ; C, \times 5400, D \times 4500)$. LB, lamellar inclusion body; $I$, type I epithelial cell; $I I$, type II epithelial cell; $U$, undifferentiated epithelial cell; $B V$, blood vessel; $G$, glycogen. 
thymidine into DNA was reflected in decreased end product, we measured the effect of estrogen on lung DNA content. We also measured lung protein content, lung weight, and total body weight. The results are shown in Table 5. Estrogen had no effect on fetal weight. However, lung wet and dry weight, protein and DNA content as well as lung weight as a fraction of fetal weight were all 8 to $15 \%$ less in the estrogen-treated group than in the controls. The protein:DNA ratio was $24 \%$ greater in the treated group.

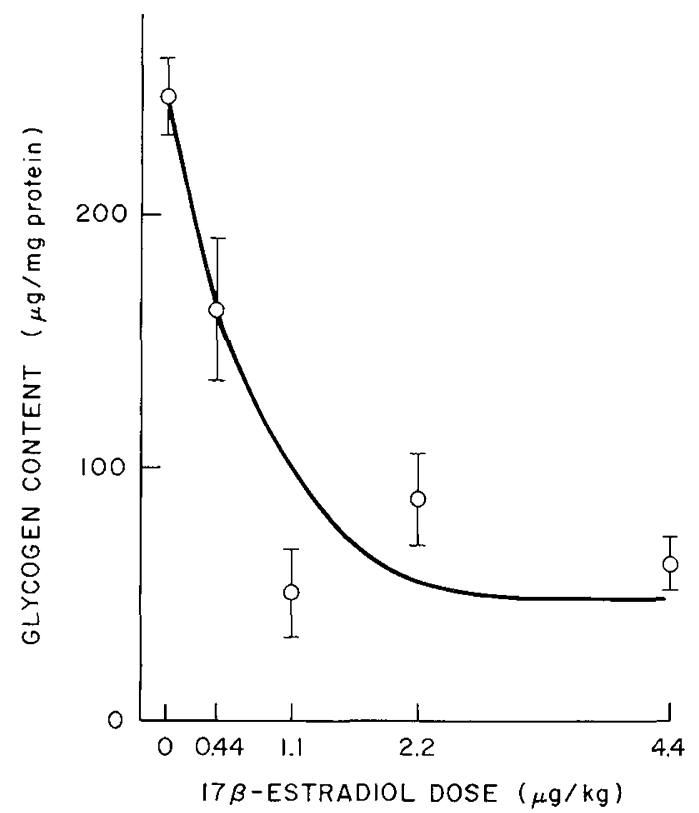

Fig. 4. The glycogen content of fetal rabbit lung at 26 days gestation after maternal administration of various doses of $17 \beta$-estradiol on day 25 . Each estrogen-treated data point is the mean of six to 11 individual fetuses from 2 to 4 litters. The control value is the mean of 47 individual fetuses from 19 litters. The $b a r$ represents \pm S.E. The differences between the estrogen-treated and control groups are statistically significant $(P<0.02$ at $0.44 \mu \mathrm{g} / \mathrm{kg} ; P<0.001$ at the higher doses).
However, these changes were not statistically significant. It is possible that if a higher dose of estrogen were used or if the animals were killed more than $24 \mathrm{hr}$ after hormone administration, the tendency towards smaller lungs with decreased DNA content would become more apparent.

\section{DISCUSSION}

Lung development in late gestation is characterized by morphologic and biochemical changes that prepare the organ for adequate postnatal gas exchange. We have previously shown that estrogen stimulates surfactant production by the fetal rabbit lung $(16,17)$. We have now extended these studies and demonstrated that estrogen accelerates morphologic maturation of the fetal lung.

Morphologic maturation of the fetal lung has been extensively reviewed by others (2). Inasmuch as maturation proceeds from apex to base, we consistently examined the right upper lobe to avoid variation in lobar development. The data show that maternal estrogen administration accelerates morphologic maturation of fetal lung as shown by the following evidence: (1) increased alveolarization; (2) increased number of alveolar epithelial type II and type I cells and decreased numbers of undifferentiated epithelial cells; (3) increased appearance of lamellar bodies in type II cells and in the alveolar lumen; and (4) decreased lung glycogen content.

Estrogen administration also resulted in maturation of the fetal lung vasculature. A similar observation was previously made by Abdul-Karim and Prior (1) who reported that administration of the anti-estrogen ethamoxytriphetol (MER-25) to pregnant rabbits resulted in the fetal lung blood vessels having thicker walls, narrower lumens, and a decreased lumen-to-wall ratio than the controls. These changes were not seen when $17 \beta$-estradiol was administered together with ethamoxytriphetol. The effect of estrogen alone, however, was not examined in that study.

When we examined the data in this study, the depletion of fetal lung glycogen after estrogen administration was striking. It has been reported elsewhere (12) that in fetal rat lung explants $17 \beta$ estradiol decreased lung glycogen although the effect was much less marked than in the present study. Glucocorticoids also decrease lung glycogen both in fetal rabbits in vivo $(8,34)$ and in

Table 3. Effect of $17 \beta$-Estradiol on fetal rabbit lung and liver glycogen content ${ }^{1}$

\begin{tabular}{ccccc}
\hline \multirow{2}{*}{$\begin{array}{c}\text { Gestational age } \\
\text { (days) }\end{array}$} & Tissue & Control & Glycogen content $(\mu \mathrm{g} / \mathrm{mg}$ protein) \\
\cline { 2 - 5 } & Lung & $247 \pm 15^{2}(47)^{3}$ & $70 \pm 9(27)$ & $<$ \\
26 & Lung & $103 \pm 13(12)$ & $13 \pm 2(13)$ & $<0.001$ \\
26 & Liver & $31 \pm 5(15)$ & $31 \pm 5(18)$ & N.S. $^{4}$ \\
\hline
\end{tabular}

${ }^{1} 17 \beta$-Estradiol $(1.1$ to $4.4 \mu \mathrm{g} / \mathrm{kg})$ or vehicle was administered to the doe $24 \mathrm{hr}$ before sacrifice. The 26 -day lung data are from $19 \mathrm{control}$ and nine treated litters, the 27 day data are from three control and three treated litters, and the liver data are from five control and seven treated litters.

${ }^{2}$ Mean \pm S.E.

${ }^{3}$ Numbers in parentheses, numbers of fetuses.

${ }^{4}$ N.S., not statistically significant $(P>0.05)$.

Table 4. Effects of 17ß-estradiol on the rates of incorporation of precursors into phospholipids, protein, and DNA in fetal rabbit lung slices $^{1}$

\begin{tabular}{|c|c|c|c|c|c|}
\hline Precursor & Product & Control & Estrogen-treated & Treated:control ratio & $P$ \\
\hline$\left[M e^{-{ }^{14}} \mathrm{C}\right]$ Choline & Phosphatidylcholine & $162 \pm 13^{2}(11)^{3}$ & $234 \pm 22$ & 1.44 & $<0.02$ \\
\hline$\left[1,2{ }^{14} \mathrm{C}\right]$ Ethanolamine & Phosphatidylethanolamine & $16.3 \pm 2.8$ & $17.5 \pm 2.6 \quad(6)$ & 1.06 & N.S. ${ }^{4}$ \\
\hline $\mathrm{L}-\left[U-{ }^{14} \mathrm{C}\right]$ Leucine & Protein & $188 \pm 18$ & $174 \pm 10(10)$ & 0.93 & N.S. \\
\hline
\end{tabular}

${ }^{1} 17 \beta$-Estradiol $(0.44 \mu \mathrm{g} / \mathrm{kg})$ or vehicle was administered to the doe on day 25 of gestation, and the fetuses were delivered on day 26. Lung slices from several fetuses in each litter were pooled. Data are expressed as $\mathrm{cpm} / \mathrm{min} / \mathrm{mg}$ protein.

${ }^{2}$ Mean \pm S.E.

${ }^{3}$ Numbers in parentheses, number of litters.

${ }^{4}$ N.S., not statistically significant $(P>0.05)$. 
Table 5. Effect of $17 \beta$-estradiol on fetal rabbit weight, lung weight, and lung composition ${ }^{1}$

\begin{tabular}{lccccc}
\hline & \multicolumn{2}{c}{ Control } & \multicolumn{2}{c}{ Treated:control } \\
ratio
\end{tabular}

${ }^{1} 17 \beta$-Estradiol $(0.44 \mu \mathrm{g} / \mathrm{kg})$ or vehicle was administered to the does on day 25 of gestation, and the fetuses were delivered on day 26 . The fetal weight data are from five control and seven estrogen-treated litters. All other data are from three control and three estrogen-treated litters. The differences between the two groups were not statistically significant $(P>0.05)$.

${ }^{2}$ Mean \pm S.E.

${ }^{3}$ Numbers in parentheses, number of fetuses.

fetal rat lung explants (13). Thyroxine (13), as well as aminophylline, and cyclic adenosine $3^{\prime}: 5^{\prime}$ monophosphate (22), other agents which accelerate fetal lung maturation (33), also decreases fetal lung glycogen. On the other hand, insulin, which appears to delay fetal lung maturation, increases the glycogen content of fetal rat lung explants (11). Thus, agents which stimulate fetal lung maturation and surfactant production decrease fetal lung glycogen whereas an agent which may delay fetal lung maturation has the opposite effect. During normal development, there is a decrease in fetal lung glycogen towards the end of gestation $(4,23,36)$. In the rabbit, this occurs about the time lamellar inclusions in type II cells appear (18). In the rat, it coincides with the increase in the rate of holine incorporation into phosphatidylcholine (23). The temporal relationship between glycogen depletion and events associated with increased surfactant production has led to speculation that glycogen may provide substrate or energy for surfactant production $(18,23)$. A direct precursor-product relationship, however, has not been demonstrated.

In comparing results from investigations conducted by this laboratory and others on lung maturation, a number of noteworthy similarities were found between the effects of estrogen and glucocorticoids. Both accelerate morphologic maturation of the fetal lung (18) and deplete its glycogen content $(8,34)$. Both increase the amount of phosphatidylcholine as well as the phosphatidylcholine:sphingomyelin ratio in lung lavage and increase the rate of choline incorporation into phosphatidylcholine in lung slices (33). Both hormones stimulate fetal lung cholinephosphate cytidylyltransferase and lysolecithin acyltransferase activities (33). In contrast, glucocorticoids stimulate fetal lung phosphatidate phosphatase $(5,30,34)$, whereas estrogen does not (16). Estrogen increases the amount of total phospholipid and phosphatidycholine in lavaged lung tissue (17) whereas glucocorticoids do not (34).

Fetal body weights have been reported to be both unaffected (6) and decreased $(27,30)$ by glucocorticoids. Fetal lung weights and lung weight:body weight ratios were decreased by glucocorticoids $(6,30)$ as were fetal lung protein and DNA contents $(6)$. The rates of incorporation of methionine into protein (30) and of thymidine into DNA (35) were also decreased by glucocorticoids. Except for the incorporation of thymidine into DNA, this study demonstrates that the effects of estrogen on these parameters were not statistically significant but tended to produce the same results as did the effects of glucocorticoids. These findings imply that both estrogen and glucocorticoids stimulate lung differentiation at the expense of lung growth.

It is now generally accepted that the effects of glucocorticoids on fetal lung are mediated via glucocorticoid receptors (3). Estrogens do not bind to the glucocorticoid receptor in the fetal lung (3). Thus, estrogens must act via another mechanism. Inasmuch as estrogen accelerates the maturation of fetal rat lung explants in vitro (12), it is likely that it acts directly on the lung rather than indirectly via other organs. Estrogen receptors have been reported in adult rat lung (26) and fetal guinea pig lung (29). Recent studies by Mendelson et al. (25) on the human fetus and by Khosla et al. (unpublished observations) on the fetal rabbit in this laboratory have shown that the estrogen binder in fetal lung is not the classical estrogen receptor. The role, if any, of the estrogen binder in mediating the effects of estrogen on fetal lung maturation is not clear.

A role for sex hormones in the regulation of fetal lung maturation is suggested by recent reports. Both in humans (28) and rabbits (19), female fetal lungs are more mature than those of males at the same gestational age. Umbilical artery $17 \beta$-estradiol levels were significantly higher in female fetal rhesus monkeys than in males after 150 days gestation (31). There was little difference between the sexes before 150 days. In midgestation human pregnancies, amniotic fluid $17 \beta$-estradiol levels were also higher in female fetuses than in males (32). However, androgen levels were higher in male fetuses (32).

In summary, the data in this paper together with previous data from this laboratory $(12,16,17)$ show that estrogen can accelerate fetal lung maturation and stimulate pulmonary surfactant production. Estrogen levels are known to increase towards the end of gestation in many species. In the human, the increase in plasma estrogens during pregnancy (20) appears to precede the surge in surfactant production by the fetus as determined by an increase in the amniotic fluid lecithin:sphingomyelin ratio (14). Low fetal estrogen levels have been reported to be associated with the respiratory distress syndrome (9). It is possible that estrogens play a role in the physiologic regulation of fetal lung maturation. However, there is as yet no direct evidence in support of this.

\section{REFERENCES AND NOTES}

1. Abdul-Karim, R. W., and Prior, J. T.: The influence of estrogens on the lung vasculature of the premature rabbit neonate. J. Reprod. Med., 2: 140 (1969).

2. Alcorn, D. G., Alexander, I. G. S., Maloney, J. E., Ritchie, B. C., and Walker, A. M.: Morphological development of the lung: a review. Aust. Paediatr. J., 10: 189 (1974).

3. Ballard, P. L.: Glucocorticoid receptors in the lung. Fed. Proc., 36: 2660 (1977).

4. Brandstrup, N., and Kretchmer, N.: The metabolism of glycogen in the lungs of the fetal rabbit. Dev. Biol., 11: 202 (1965).

5. Brehier, A., Benson, B. J., Williams, M. C., Mason, R. J., and Ballard, P. L.: Corticosteroid induction of phosphatidic acid phosphatase in fetal rabbit lung. Biochem. Biophys. Res. Commun., 77: 883 (1977).

6. Carson, S. H., Tauesch, H. W., Jr., and Avery, M. E.: Inhibition of lung cell division after hydrocortisone injection into fetal rabbits. J. Appl. Physiol., 34: 660 (1973).

7. Epstein, M. F., and Farrell, P. M.: The choline incorporation pathway: primary mechanism for de novo lecithin synthesis in fetal primate lung. Pediatr. Res., 9: 658 (1975).

8. Gilden, C., Sevanian, A., Tierney, D. F., Kaplan, S. A., and Barrett, C. T.: Regulation of fetal lung phosphatidytcholine synthesis by cortisol: role of glycogen and glucose. Pediatr. Res., 11: 845 (1977).

9. Gross, I.: The hormonal regulation of fetal lung maturation. Clin. Perinatol., 6: 377 (1979). 
10. Gross, I., Smith, G. J. W., Maniscalco, W. M., Czajka, M. R., Wilson, C. M., and Rooney, S. A.: An organ culture model for study of biochemical development of fetal rat lung. J. Appl. Physiol., 45: 355 (1978).

11. Gross, I., Smith, G. J. W., Wilson, C. M., Maniscalco, W. M., Ingleson, L. D., Brehier, A., and Rooney, S. A.: The influence of hormones on biochemical development of fetal rat lung in organ culture. II. Insulin. Pediatr. Res., I4: 834 (1980).

12. Gross, I., Wilson, C. M., Ingleson, L. D., Brehier, A., and Rooney, S. A.: The influence of hormones on the biochemical development of fetal rat lung in organ culture. I. Estrogen. Biochim. Biophys. Acta, 575: 375 (1979).

13. Gross, I., Wilson, C. M., Ingleson, L. D., Brehier, A., and Rooney, S. A.: Fetal lung in organ culture. III. Comparison of dexamethasone, thyroxine and methylxanthines. J. Appl. Physiol., 48: 872 (1980).

14. Hauth, J. C., Parker, C. R., MacDonald, P. C., Porter, J. C., and Johnston, J. M.: A role of fetal prolactin in lung maturation. Obstet. Gynecol., 51: 81 (1978).

15. Hill, B. T., and Whatley, S.: A simple, rapid microassay for DNA. FEBS Lett., 56: 20 (1975).

16. Khosla, S. S., Gobran, L. I., and Rooney, S. A.: Stimulation of phosphatid; ${ }^{\text {tr }}$ holine synthesis by $17 \beta$-estradiol in fetal rabbit lung. Biochim. Biophys. Acta, 617: 282 (1980).

17. Khosla, S. S., and Rooney, S. A.: Stimulation of fetal lung surfactant productinn by administration of $17 \beta$-estradiol to the maternal rabbit. Am. J. Obstet. Gynecol., 133: 213 (1979).

18. Kikkawa, Y., Kaibara, M., Motoyama, E. K., Orzalesi, M. M., and Cook, C. D.: Morphologic development of fetal rabbit lung and its acceleration with cortisol. Am. J. Pathol, 64: 423 (1971).

19. Kotas, R. V., and Avery, M. E.: The influence of sex on fetal rabbit lung maturation and on the response to glucocorticoid. Am. Rev. Respir. Dis., 121: 377 (1980).

20. Levitz, M., and Young, B. K.: Estrogens in pregnancy. Vitam. Horm., 35: 109 (1977).

21. Lowry, O. H., Rosebrough, N. J., Farr, A. L., and Randall, R. J.: Protein measurement with the Folin phenol reagent. J. Biol. Chem., 193: 265 (1951).

22. Maniscalco, W. M., Wilson, C. M., and Gross, I.: Influence of aminophylline and cyclic AMP on glycogen metabolism in fetal rat lung in organ culture. Pediatr. Res., 13: 1319 (1979).

23. Maniscalco, W. M., Wilson, C. M., Gross, I., Gobran, L., Rooney, S. A., and Warshaw, J. B.: Development of glycogen and phospholipid metabolism in fetal and newborn rat lung. Biochim. Biophys. Acta, 530: 333 (1978).

24. Mans, R. J., and Novelli, G. D.: Measurement of the incorporation of radioactive amino acids into protein by a filter paper disk method. Arch. Biochem. Biophys., 94: 48 (1961).

25. Mendelson, C. R., MacDonald, P. C., and Johnston, J. M.: Estrogen binding in human fetal lung tissue cytosol. Endocrinology, 106: 368 (1980).
26. Morishige, W. K., and Uetake, C. A.: Receptors for androgen and estrogen in the rat lung. Endocrinology, 102: 1827 (1978).

27. Motoyama, E. K., Orzalesi, M. M., Kikkawa, Y., Kaibara, N., Wu, B., Zigas, C. J., and Cook, C. D.: Effect of cortisol on the maturation of fetal rabbit lungs. Pediatrics, 48 : 547 (1971).

28. Nielsen, H. C., Torday, J. S., Fencl, M., and Avery, M. E.: Sex differences in human fetal lung maturation. Pediatr. Res., 13: 361 (1979).

29. Pasqualini, J. R., Sumida, C., Gelly, C., and Nguyen, B.: Specific [3 H]-estradiol binding in the fetal uterus and testis of guinea pig. Quantitative evolution of $\left[{ }^{3} \mathrm{H}\right]$-estradiol receptors in the different fetal tissues (kidney, lung, uterus and testis) during fetal development. J. Steroid Biochem., 7: 1031 (1976).

30. Possmayer, F., Casola, P., Chan, F., Hill, S., Metcalfe, I. L., Stewart-DeHaan, P. J., Wong, T., Las Heras, J., Gammal, E. B., and Harding, P. G. R.: Glucocorticoid induction of pulmonary maturation in the rabbit fetus. The effect of maternal injection of betamethasone on the activity of enzymes in fetal lung. Biochim. Biophys. Acta, 574: 197 (1979).

31. Resko, J. A., Ploem, J. G., and Stadelman, H. L.: Estrogens in fetal and maternal plasma of the rhesus monkey. Endocrinology, 97: 425 (1975).

32. Robinson, J. D., Judd, H. L., Young, P. E., Jones, O. W., and Yen, S. S. C.: Amniotic fluid androgens and estrogens in midgestation. J. Clin. Endocrinol. Metab., 45: 755 (1977).

33. Rooney, S. A.: Biosynthesis of lung surfactant during fetal and early postnatal development. Trends Biochem. Sci., 4: 189 (1979).

34. Rooney, S. A., Gobran, L. I., Marino, P. A., Maniscalco, W. M., and Gross, I.: Effects of betamethasone on phospholipid content, composition and biosynthesis in the fetal rabbit lung. Biochim. Biophys. Acta, 572: 64 (1979).

35. Sanfacon, R., Possmayer, F., and Harding, P. G. R.: Dexamethasone treatment of guinea pig fetus: its effects on the incorporation of ${ }^{3} \mathrm{H}$-thymidine into deoxyribonucleic acid. Am J. Obstet. Gynecol, 127: 745 (1977).

36. Shelly, H. J.: Glycogen reserves and their changes at birth and in anoxia. Br. Med. Bull., 17: 137 (1961)

37. Weibel, E. R.: Principles and methods for the morphometric study of the lung and other organs. Lab. Invest., 12: 131 (1963).

38. A preliminary report of this work was presented at the 64th Annual Meeting of the Federation of American Societies for Experimental Biology, Anaheim, California, April 13-18, 1980.

39. The authors thank Donna Light for technical assistance.

40. Requests for reprints should be addressed to: Seamus A. Rooney, Ph.D., Yale Department of Pediatrics, 333 Cedar Street, P.O. Box 3333, New Haven, CT 06510 (USA).

41. This research was supported by Grant HD-10192 from the National Institute of Child Health and Human Development.

42. Received for publication November 5, 1980

43. Accepted for publication February 3, 1981. 